\title{
Drug-Resistant Tuberculosis in South-Western Nigeria: A Case Series
}

\author{
Adekunle Olatayo Adeoti $^{1 *}$, Olabode Oguntiloye ${ }^{2}$, Ayodele Seluwa ${ }^{3}$, Adebayo Orojo ${ }^{4}$ \\ ${ }^{I}$ Respiratory Unit, Department of Medicine, Ekiti State University Teaching Hospital, Ado-Ekiti, Nigeria \\ ${ }^{2}$ Department of Medicine, Ekiti State University Teaching Hospital, Ado-Ekiti, Nigeria \\ ${ }^{3}$ Infectious disease Unit, Ekiti State Ministry of Health, Ado-Ekiti, Nigeria \\ ${ }^{4}$ Infectious Disease Unit, Ekiti State Ministry of Health, Ado-Ekiti, Nigeria
}

*Corresponding Author: Adekunle Olatayo Adeoti, Respiratory Unit, Department of Medicine, Ekiti State University Teaching Hospital, Ado-Ekiti, Nigeria, Email: Kadeoti2002@yahoo.com

\begin{abstract}
Background: The emergence of drug-resistant tuberculosis (DR-TB) has seriously hampered the control of $T B$ globally. We, therefore, evaluated the treatment outcome of DR-TB cases managed, as there was no previous report in Ekiti state, south-western, Nigeria.
\end{abstract}

Methods: A retrospective study of patients managed for DR-TB from January 2010 to December 2016. Demographic, laboratory and clinical characteristics were obtained from the centralized DR-TB register and patients' case notes. Culture and drug susceptibility testing were carried out at the zonal reference laboratory.

Results: 18 patients were diagnosed with DR-TB during this period with 17 MDR-TB and 1 mono-resistance case $(R R-T B)$. Treatment outcome revealed 11 treatment successes, 4deaths, 2 refused treatments and 1 lost to follow up.

Conclusion: Despite the relatively low occurrence of DR-TB in this region, scaling up public awareness will be necessary to further reduce mortality and improve treatment outcome so as to achieve the goal to end TB epidemic and forestalling increase in the incidence of more resistant strains.

\section{INTRODUCTION}

Drug-resistant TB (DR-TB) threatens global TB control and remains a major public health concern which results from the spontaneous emergence of resistant strains to antituberculous medications. ${ }^{1}$ More toxic, expensive, less effective, associated with a greater incidence of adverse reactions. The second line drugs are more toxic administered for longer treatment duration than first-line drugs. ${ }^{1,2}$ Rifampicinresistant TB(RR-TB), a form of mono-resistance to only Rifampicin while multi-drug resistant TB (MDR-TB) is resistance to at least isoniazid and rifampicin. ${ }^{3}$

In 2016, the World Health Organization (WHO) reported 10.4 million new TB cases worldwide, $3.9 \%$ were estimated to have had rifampicin- or multidrug-resistant tuberculosis (MDR/RRTB). ${ }^{3}$ Nigeria is one of the high TB burden countries and the national DR-TB survey reported the prevalence of MDR-TB in Nigeria as $2.9 \%$ of new TB cases and $14.3 \%$ of retreatment cases. ${ }^{4}$ There has been an increasing trend in MDR-TB in both new and retreatment cases in country. ${ }^{5}$

The risks for DR-TB include exposure to patients with DR-TB, non-adherence of patients with drug-sensitive TB (DS-TB) to medications, relapse of $\mathrm{TB}$, living in a region where DR-TB is endemic and HIV infection. ${ }^{4}$, ${ }^{5}$ The reemergence of TB has been attributed to the HIV epidemics, which also fuels an increase in the prevalence of DR-TB. ${ }^{5}$

The reported success rate by the WHO in 2016 in the treatment of MDR-TB was 52\%, hence concerted effort is required to improve on the treatment success rate if we will achieve the global goal of eliminating TB by the year 2030. ${ }^{1}$ Furthermore, if MDR-TB is improperly managed, it may result in the emergence of 
extensively drug-resistant TB (XDR-TB). It is, therefore, imperative to review the treatment outcomes of DR-TB in our region in order to audit our practice.

There has been no previous study on DR-TB in this region, althougha few documentations are available in other parts of the country. ${ }^{6}$ The study period aimed to determine the treatment outcome and identifiable predisposing factors to DR-TB managed in the state.

\section{METHODS}

This is a retrospective study involving patients who were diagnosed and treated for DR-TB between January 2010 and December 2016 in Ekiti state, located in south western region of Nigeria. Ekiti state is located within $7^{0} 40^{\mathrm{I}} \mathrm{N} 5^{0}$ $15^{\mathrm{I}} \mathrm{E}$ with an estimated population of $2,384,212$ as at 2006 population census and a density of $380 / \mathrm{km}^{2}$. It is mainly an upland zone, rising over 250 meters above sea level and a tropical climate with temperature ranging between $21^{0}$ to $28^{0} \mathrm{C}^{7}$

Data was obtained from Ekiti state central DRTB register and patients' case note were complemented by the zonal DR-TB reference laboratory results comprising of the specimen culture and drug susceptibility testing. The obtained information included patients' demographic characteristics, previous history of TB treatment, HIV status, exposure to any known DR-TB patients, adherence to previous anti-tuberculous medications and treatment outcome.

The zonal DR-TB reference laboratory provided data on the drug resistance profile of isolates obtained through culture and drug susceptibility testing for all cases reported during study period. The laboratory provided drug-resistant testing to first and second-line anti-TB drugs using BACTEC MGIT 960 and proportion method on solid medium respectively.

They were commenced on treatment and monitored for adverse reaction to the medication based on the national guideline. ${ }^{4}$ Conventional MDR/RR-TB regimens were used to treat all patients in this study for a period 20 months, before adopting recently the shorter treatment course. All the 18 patients received the following drugs; kanamycin injection, prothionamide, cycloserine, levofloxacin, pyrazinamide and pyridoxine.

Treatment outcome was defined in accordance with WHO guidelines for multi-drug-resistant tuberculosis patients as shown below.
Treatment outcome definitions for multidrugresistant tuberculosis patients

\begin{tabular}{|l|l|}
\hline Cured & $\begin{array}{l}\text { Treatment completed with at least } \\
\text { three negative cultures taken after } \\
\text { the intensive phase in the absence } \\
\text { of treatment failure. }\end{array}$ \\
\hline $\begin{array}{l}\text { Treatment } \\
\text { completed }\end{array}$ & $\begin{array}{l}\text { Treatment completed without } \\
\text { evidence of failure but no record of } \\
\text { at least three consecutive negative } \\
\text { cultures taken at least three negative } \\
\text { cultures after the intensive phase. }\end{array}$ \\
\hline $\begin{array}{l}\text { Treatment } \\
\text { failed }\end{array}$ & $\begin{array}{l}\text { Treatment terminated or need for } \\
\text { permanent regimen change of at } \\
\text { least two anti-TB drugs. }\end{array}$ \\
\hline Died & $\begin{array}{l}\text { A patient who dies for any reason } \\
\text { during the course of treatment. }\end{array}$ \\
\hline $\begin{array}{l}\text { Lost to } \\
\text { follow-up }\end{array}$ & $\begin{array}{l}\text { A patient whose treatment was } \\
\text { interrupted for } 2 \\
\text { months or more. }\end{array}$ \\
\hline $\begin{array}{l}\text { Not } \\
\text { evaluated }\end{array}$ & $\begin{array}{l}\text { A patient for whom no treatment } \\
\text { outcome is assigned. }\end{array}$ \\
\hline $\begin{array}{l}\text { Treatment } \\
\text { success }\end{array}$ & $\begin{array}{l}\text { The sum of cured and treatment } \\
\text { completed. }\end{array}$ \\
\hline
\end{tabular}

Culled from World health organization guidelines ${ }^{4}$

\section{RESUlts}

Eighteen patients were culture-confirmed cases of drug resistant tuberculosis during the study period, 11 males and 7 females (male to female ratio 1.6 to 1 ).The median age was 30.5 years(age range from 18 to 65 years). Majority of the cases were unemployed and none of the three employed individuals were health care workers.

All the patients were born in Nigeria, and16 were previously treated for TB but they were non-adherent to medication during the period of treatment. There were two co-infected cases of DR-TB and HIV who were also on antiretroviral medications. Of the 18 cases, two had close contact with individuals on treatment for MDRTB patients, who were either their spouse or sibling respectively. Positive culture results and drug susceptibility testing were reported in all patients. Seventeen patients were diagnosed as MDR-TB while only one case was diagnosed with rifampicin-resistant TB (mono-resistance). The average length of treatment for those who completed therapy was 20 months. However, two patients refused treatment despite persuasion and counseling, one was lost to follow-up after the initial commencement of therapy while four patients died in the course of treatment. Treatment success was recorded in 11 patients. 


\section{DISCUSSION}

The study is a case series to highlight the treatment outcome of DR-TB managed in a region with relatively lower prevalence of $\mathrm{TB}$ in Nigeria but surrounded by states with higher disease burden.

The majority of the subjects were males which was similar to what was reported in other regions in the country. ${ }^{5,8}$ This could be due to the higher likelihood for habits like consumption of alcohol as well as smoking habits. On the contrary, another report found no significant association between rifampicin resistance and gender. ${ }^{8}$

A major risk factor is the country of birth especially high burden countries, this is important as all patients were born in and have lived in Nigeria, one of the high TB burden countries. ${ }^{9,10}$ Similarly, previous diagnosis and treatment of tuberculosis have a strong association with the development of resistant strain either due to poor adherence to treatment regimens, inadequate dosing or emergence of mutant strains. ${ }^{4-6}$ Furthermore, more than half of previously treated TB patients in Nigeria were resistant to at least one first-line anti-TB drug, and overall $32 \%$ had MDR-TB. ${ }^{6}$

Due to the strong association between HIV and tuberculosis, screening of all TB patients for HIV and vice versa is routine in our clinical practice. In this report, 2 patients had HIV/ DRTB co-infection which could be due to the low prevalence $(0.2 \%)$ of HIV in the state as it is one of the lowest in the country. ${ }^{11}$ This is similar to

Table1. Demography of MDR-TB cases in Ekiti, 2010 - 2016

\begin{tabular}{|l|l|l|l|l|l|l|}
\hline Case & Age (years) & Sex & $\begin{array}{l}\text { Year of } \\
\text { diagnosis }\end{array}$ & Drug sensitivity & $\begin{array}{l}\text { Duration of } \\
\text { treatment }\end{array}$ & Treatment outcome \\
\hline 1 & 34 & Male & 2012 & MDR & 20 months & Completed \\
\hline 2 & 45 & Male & 2013 & MDR & 20 months & Completed \\
\hline 3 & 24 & Male & 2014 & MDR & Loss to follow-up & Loss to follow up \\
\hline 4 & 52 & Male & 2014 & MDR & 20 months & Completed \\
\hline 5 & 30 & Male & 2014 & MDR & Refused treatment & Refused treatment \\
\hline 6 & 37 & Female & 2015 & MDR & 20 months & Completed \\
\hline 7 & 29 & Male & 2014 & MDR & 20 months & Completed \\
\hline 8 & 42 & Female & 2015 & MDR & Died at $1^{\text {st } \text { month }}$ & Died \\
\hline 9 & 22 & Male & 2015 & MDR & Died at $9^{\text {th } \text { month }}$ & Died \\
\hline 10 & 65 & Female & 2015 & MDR & Refused treatment & Refused treatment \\
\hline 11 & 26 & Male & 2010 & MDR & Died at $6^{\text {th } \text { month }}$ & Died \\
\hline 12 & 22 & Male & 2010 & MDR & Died at $4^{\text {th } \text { month }}$ & Died \\
\hline 13 & 18 & Female & 2016 & MDR & 20 months & Completed \\
\hline 14 & 25 & Female & 2016 & MDR & 20 months & Completed \\
\hline 15 & 44 & Female & 2016 & MDR & 20 months & Completed \\
\hline 16 & 40 & Female & 2016 & MDR & 20 months & Completed \\
\hline 17 & 26 & Male & 2016 & MDR & 20 months & Completed \\
\hline 18 & 31 & Male & 2016 & Rifampicin- & 20 months & Completed \\
& & & & & & \\
\hline
\end{tabular}

the reports from other studies in Nigeria in which HIV infection is not significantly associated with the development of DR-TB., ${ }^{5,12,13}$

There was no reported case of extrapulmonary DR-TB among the study group which could be due to the challenge of specimen collection. Likewise, those requiring broncho-alveolar lavage or forced sputum production mainly due to risk of contracting the infection and the nonavailability of the required equipment.

Most of the deaths were recorded in the early phase of treatment which could be due to severe immunosuppression at presentation, degree of resistance to anti-tuberculosis drugs and malnutrition. ${ }^{16}$

Patients who refused treatment or were lost to follow up constitute a great hazard to the community especially to the vulnerable underfive children and immune-compromised individuals. Therefore, policy formulation is essential in restricting the movement of such patients as they are continually counseled on the benefits of receiving treatment without infringing on ethical codes.

Our series has some limitations, being a retrospective study with fewer subjects study; caution must therefore be taken in generalizing hence a larger cohort of patients recruited from several treatment centres would be more reflective. It is however, anticipated that this study will give insight into the experience in the management of DR-TB in a region with few reported cases. 
Table2. Risk factors for MDR-TB cases, Ekiti state, 2010 -2016

\begin{tabular}{|l|l|l|l|l|}
\hline Case & $\begin{array}{l}\text { Previous diagnosis of } \\
\text { TB/Exposure to treatment }\end{array}$ & $\begin{array}{l}\text { Suspected non-adherence or } \\
\text { inappropriate TB therapy }\end{array}$ & $\begin{array}{l}\text { Exposure to a known } \\
\text { MDR-TB case }\end{array}$ & HIV status \\
\hline 1 & Yes & Yes & No & Negative \\
\hline 2 & Yes & Yes & No & Negative \\
\hline 3 & Yes & Yes & No & Negative \\
\hline 4 & Yes & Yes & No & Negative \\
\hline 5 & Yes & Yes & No & Negative \\
\hline 6 & Yes & Yes & No & Negative \\
\hline 7 & Yes & Yes & No & Negative \\
\hline 8 & Yes & Yes & No & Negative \\
\hline 9 & Yes & Yes & No & Negative \\
\hline 10 & Yes & Yes & No & Negative \\
\hline 11 & Yes (Twice) & Yes & No & Negative \\
\hline 12 & No & No & Yes & Negative \\
\hline 13 & Yes & Yes & No & Negative \\
\hline 14 & Yes & Yes & No & Negative \\
\hline 15 & Yes & Yes & No & Positive \\
\hline 16 & No & No & Yes & Positive \\
\hline 17 & Yes & Yes & No & Negative \\
\hline 18 & Yes (Twice) & Yes & No & Negative \\
\hline
\end{tabular}

Table3. Summary of treatment outcome

\begin{tabular}{|l|l|}
\hline Treatment outcome & Percentage (\%) \\
\hline Treatment Completed & $11(61.0 \%)$ \\
\hline Died & $4(22.0 \%)$ \\
\hline Refused treatment & $2(11.0 \%)$ \\
\hline Lost To Follow-Up & $1(6.0 \%)$ \\
\hline
\end{tabular}

\section{CONCLUSION}

There is a need to strengthen the TB programme by developing more rapid diagnostic and drug susceptibility tests for DR-TB as well as the discovery of more effective, less toxic drugs for shorter duration to prevent the emergence of extensive drug resistant TB (XDR-TB). Furthermore, integrating the community and scaling up public awareness will enhance early identification of suspected cases in the community with the provision of the necessary support for the commencement and completion of treatment.

\section{ETHICAL CONSIDERATIONS}

Confidentiality of the data collected was maintained and ethical approval was obtained from the Ekiti State University Teaching Hospital ethical committee.

\section{REFERENCES}

[1] World Health Organization. Global Tuberculosis Control: WHO report 2016. Geneva, Switzerland: World Health Organization, 2016. http.who.int/tb/public cations/global_report/gtbr2016_executive_sum $\mathrm{m}$ ary.pdf

[2] Kibret KT, Moges Y, Memiah P, Biadgilign S. "Treatment Outcomes for Multidrug-Resistant Tuberculosis under DOTS-Plus: A Systematic Review and Meta-Analysis of Published
Studies." Infectious Diseases of Poverty (2017) 6: 7 DOI 10.1186/s40249-016-0214-x

[3] WHO treatment guidelines for drug-resistant tuberculosis, 2016 update. Available from http://apps.who.int/iris/bitstream/10665/25012 5/1/9789241549639-eng.pdf

[4] Guidelines for programmatic and clinical management of drug resistant tuberculosis in Nigeria. $2^{\text {nd }}$ edition. 2016.

[5] Uzoewulu NG, Ibeh IN, Lawson L, Goyal M, Umenyonu N, et al. Drug Resistant Mycobacterium tuberculosis in Tertiary Hospital South East, Nigeria. J Med MicrobDiagn 2014 3: 141. doi:10.4172/21610703. 1000141

[6] Onyedum CC, Alobu I, Ukwaja KN Prevalence of drug-resistant tuberculosis in Nigeria: A systematic review and meta-analysis. PLoS ONE 2017 12(7): e0180996. https://doi.org/ 10. 1371/journal.pone. 0180996

[7] Ekiti state. Available from https://en.wikipediaorg/wiki/list of Nigerian_states by population

[8] Nwadioha SI, Nwokedi EO, Ezema GC, Eronini NC, Anikwe A, Audu F, Onwuezobe I. Drug Resistant Mycobacterium tuberculosis in Benue, Nigeria.British Microbiology Research Journal, 2014; 4(9): 988-995.

[9] Roberts-Witteveen A, Reinten T, Christensen A, Sintchenko V, Seale P, Lowbridge C. Multidrug-resistant tuberculosis in New South Wales, Australia, 1999-2010: a case series 
report. The International Journal of Tuberculosis and Lung Disease. 2015 Jul 1; 19 (7):850-6.

[10] Judge D, Krause VL. Multidrug-resistant tuberculosis in the Northern Territory: A 10year retrospective case series. Daniel judge, Krause V. L. multidrug-resistant tuberculosis in the northern territory: a 10-year retrospective case series. Commun Dis Intell 2016; 40(3): E334-E339.

[11] NARHS-Plus-2012-Final. Available from https://naca.gov.ng/narhs-plus-2012-final.

[12] Ani AE, Idoko J, Dalyop YB, Pitmang SL. Drug Resistant profile of Mycobacterium tuberculosis isolates from pulmonary tuberculosis patients in Jos, Nigeria. Trans R Soc Trop Med Hyg 2009; 103:67-71
[13] Otu A, Umoh V, Habib A, Ameh S, Lawson L, Ansa V. Drug Resistance among Pulmo Tuberculosis patients in Calabar, Nigeria. Pulm Med 2013; 2013: 235190.doi:10.1155 /2013/ 23 5190.

[14] Mohan $\mathrm{k}$ manu et al, Extrapulmonary Multidrug Resistant Tuberculosis Presenting As Chest Wall Abscess -A Rare Case Report. Indian J Tuberc 2013; 60: 121 - 123

[15] Mittal N and Bansal P. Multidrug resistant extrapulmonary tuberculosis - three case reports and review of literature. Intern Med Inside. 2014; 2:2. http://dx.doi.org/ 10.7243/ 2052-6954-2-2

[16] Mollie E. W, Chilongola J. O. predictors for mortality among multi-drug resistant tuberculosis patients in Tanzania. Journal of tropical medicine volume 2017 article id 9241238, 6 pages https://doi.org/ 10.1155/ 2017/9241238

Citation: Adekunle Olatayo Adeoti, Olabode Oguntiloye, Ayodele Seluwa, Adebayo Orojo. Drug-Resistant Tuberculosis in South-Western Nigeria: A Case Series. ARC Journal of Clinical Case Reports. 2018; 4(1): 1-5. doi:dx.doi.org/10.20431/2455-9806.0401001.

Copyright: (C) 2018 Authors. This is an open-access article distributed under the terms of the Creative Commons Attribution License, which permits unrestricted use, distribution, and reproduction in any medium, provided the original author and source are credited. 